\title{
DIFFERENT SEEDLING RAISING METHODS AFFECT CHARACTERISTICS OF MACHINE-TRANSPLANTED RICE SEEDLINGS
}

\author{
ChENG, S. R. ${ }^{1,2 \dagger}-$ AshraF, U. ${ }^{1,3 \dagger}-$ ZhANG, T. T. ${ }^{1,2 \dagger}-$ Mo, Z. W. ${ }^{1,2}-$ KONG, L. L. ${ }^{1}-$ MAI, Y. X. ${ }^{1}-$ \\ HUANG, H. L. ${ }^{1}-$ TANG, X. R. ${ }^{1,2 *}$ \\ ${ }^{I}$ Department of Crop Science and Technology, College of Agriculture, South China Agricultural \\ University, Guangzhou, Guangdong 510642, China \\ ${ }^{2}$ Scientific Observing and Experimental Station of Crop Cultivation in South China, Ministry of \\ Agriculture of the P. R. China, Guangzhou, Guangdong 510642, China \\ ${ }^{3}$ Department of Agronomy, University of Agriculture \\ Faisalabad 38040, Pakistan \\ ${ }^{\dagger}$ These authors have contributed equally to this work. \\ *Corresponding author \\ e-mail: tangxr@scau.edu.cn; phonelfax: +86-20-8528-0204-618 \\ (Received $4^{\text {th }}$ Oct 2017; accepted $12^{\text {th }}$ Feb 2018)
}

\begin{abstract}
Present study was aimed to select the suitable seedling raising method with high seedling quality for the machine-transplanted rice. The seeds of two rice cultivars i.e., Xiangyaxiangzhan and Wufengyou 615 were grown under four different seedling-raising methods i.e., the traditional seedlingraising method (TWSM), the dry seedbed nursery raising method (DSBM), the wet seedbed raising method (WSBM), and the substrate seedbed nursery raising method (SSBM). Results showed that the highest seed germination and seedling establishment rates were recorded in SSBM followed by DSBM, and TWSM. Rice seedlings grown in SSBM have maximum seedling length, longer leaves and leaf sheath as well as dry biomass than other establishment methods. Further, number of roots, root length, root surface area and root diameter were also found significantly $(P \leq 0.05)$ higher than those seedlings which were established by normal farmer practice (TWSM). Additionally, higher proline, protein and soluble sugars contents and SPAD values (an indicator of chlorophyll contents) were also recorded in SSBM. Hence, SSBM would result in improved rice seedlings, compared to those under traditional nursery, dry bed nurse and wet bed nursery.

Keywords: physiological character, root growth, rice nursery, seed germination, seedling-raising methods
\end{abstract}

\section{Introduction}

Rice (Oryza sativa) is the most important cereal crop that feeds more than half of the world's population (Ruiz-Sánchez et al., 2010; Abid et al., 2015; Kargbo et al., 2016). Rice ranks first among the cereal crops in China and it has been cultivated for more than 7000 years ago, feeding more than $65 \%$ of the population of China as a staple food (Ivanic and Martin, 2008). In China, rice covers an area of 30.14 million hectare with an annual production of 204.24 million tons. Hence, rice production in China contributes to food security not only for China but also for the rest of the world (Yao et al., 2007; Ashraf et al., 2015).

Seedling transplanting has many advantages over direct seeding; however, manual transplantation of rice nursery is time consuming and slow process (Ehsanullah et al., 2014) as compared with mechanical transplantation. The 
development of modern, large-scale, professional and commercial production of rice through mechanized planting plays a critical role to ensure efficient transplanting and maintaining rice productivity (Zhu et al., 2007). Presently, mechanized rice transplanting technology has been successfully adopted in Europe, America, Japan and many other developed countries, whilst in China, the mechanized transplanting is still not widely adopted. Recently, a report stated that mechanized rice transplantation was about 34\% at the end of 2014 in China (Yang et al., 2003; Li, 2015).

Healthy and well-nourished seedlings with uniform growth (grown on PVC trays to load to the machine for transplanting) are the prerequisites for uniform transplantation in the field and these seedlings must meet certain technical standards in the system of mechanical transplanting of rice seedlings (Biswas et al., 2000). To develop standard seedlings, as required by the mechanized transplantation, the compatibility among seedlings cultivation/growing method, machine operational system, quality of the rice seedlings must be considered (Zhang and Gong, 2014). Conventional nursery raising is often practiced in paddy soils which is often silty in nature (Mishra and Salokhe, 2008; Li et al., 2014) which makes the manual transplantation difficult. Thus, rather growing rice nursery in the fields, nursery raising in PVC trays and/or in nursery mat is conducive for machine transplanting. Hence, for mechanized transplanting rice technology, indoor seedling/nursery raising on artificial media can also be practiced other than outdoor nursery (that may be threatened by environmental extremities). For indoor nursery raising, seedling growing medium may largely affect the growth and development of rice seedlings. Present study thus focused to test the effect of different nursery management methods on germination, morphological growth and physiological characters of rice seedlings with the aim to determine the best possible nursery raising method for machine-transplanted rice seedlings.

\section{Materials and methods}

\section{Experimental site}

The seedlings were raised in green house located at Experimental Research Farm, College of Agriculture, South China Agricultural University, Guangzhou, China $\left(23^{\circ} 09^{\prime} \mathrm{N}, 113^{\circ} 22^{\prime} \mathrm{E}\right.$ and $11 \mathrm{~m}$ above the sea level) during 2015 . The region has subtropical monsoonal type of climate normally with yearly average temperature ranges ranged from 21 to $29{ }^{\circ} \mathrm{C}$ and $70-80 \%$ relative humidity and high rainfall during May-July ( $\mathrm{Li}$ et al., 2016; Mo et al., 2016). Moreover, the average temperature, rainfall, and relative humidity for experimental period was remained $28{ }^{\circ} \mathrm{C}, 19.17 \mathrm{~mm}$ and $79.60 \%$, respectively.

\section{Plant material and treatment description}

Seeds of two local and widely cultivated rice cultivars i.e., Xiangyaxiangzhan and Wufengyou 615, were collected from the College of Agriculture, South China Agricultural University, Guangzhou, China. Prior to sowing, seeds of both rice cultivars were soaked in water for $48 \mathrm{~h}$ in dark chamber at room temperature. Seeds were sown in four different methods i.e., (i) traditional seedling-raising method in 
which the seeds were directly sowed on the wet seedbed (TWSM) (taken as control), (ii) the dry seedbed raising method in which the seeds were sown in PVC trays covered with air dried soil collected from paddy fields, and applied with distilled water (DSBM), (iii) the wet seedbed raising method in which the seeds were sown in PVC trays covered with well cultivated puddled soil, collected from paddy fields (WSBM), and (iv) the substrate seedbed raising method in which seeds were sown in PVC trays covered with a substrate (agricultural organic waste product including rice husk, obtained from Lianyungang Heroda Fertilizer Technology Co., Ltd, China) and sprayed with distilled water (SSBM). The dimensions of PVC trays used for nursery rising was $58.5 \mathrm{~cm} \times 28.5 \mathrm{~cm}$. The seeding density of both Xiangyaxiangzhan and Wufengyou 615 were $10000-12000$ per $\mathrm{m}^{2}$.

\section{Determination of seed germination rate and seedling establishment percentage}

To determine seed germination rate and seedling establishment percentage, seedlings from an area of $15 \mathrm{~cm} \times 15 \mathrm{~cm}$ area from each establishment method were carefully uprooted (about 60 seedlings) at 15 days after sowing (DAS), washed thoroughly with tap water and then with distilled water and the seedlings were graded in to: a) full mature seedlings, and b) young seedlings (one-half of the height of the full mature seedlings). The number of full mature seedlings, young seedlings and non-germinated seeds were counted. The seed germination rate and seedling establishment percentage was recorded as:

Rice germination rate $(\%)=$ (number of full mature seedlings + number of young seedlings) / (total germinated and un-germinated seeds) $\times 100$

Percentage of seedling establishment $(\%)=($ Number of full mature seedlings $/$ total number of germinated and un-germinated seeds) $\times 100$

\section{Morpho-physiological characteristics of rice seedlings}

The seedlings of both rice cultivars at 10, 15 and 20 DAS were sampled for morpho-physiological parameters while for the estimation of physio-biochemical traits, the seedlings were separated into roots and shoots and stored at $-80{ }^{\circ} \mathrm{C}$.

Seedling length, first leaf sheath length, length of first and second leaves was measured with a measuring ruler. Seedling fresh and dry biomass (seedlings were placed in oven at $80{ }^{\circ} \mathrm{C}$ till constant weight) per 100 seedlings were recorded by an electric balance (Sartorious, Japan). The number of primary and secondary roots was counted manually whereas root length, root surface area and root diameter of 4 well mature seedlings were recorded by a root scanner (WinRHIZO, ProLA2400, Canada) according to Oršanić et al. (2011).

\section{SPAD values of seeding}

SPAD values characterized as chlorophyll contents, were recorded from 10 seedlings of each treatment with a SPAD meter 'SPAD-502' (Konica Minolta, Japan) according Asai et al. (2009) which provided a precise, rapid and nondestructive estimation of leaf chlorophyll contents. 


\section{Estimation of proline, protein and soluble sugar}

The proline content was determined according to Celik and Atak (2012). Fresh leaf samples $(0.3 \mathrm{~g})$ were homogenized with $4 \mathrm{~mL}$ of $3 \%$ sulfosalicylic acid and heated at $100{ }^{\circ} \mathrm{C}$ for $10 \mathrm{~min}$. After cooling, $2 \mathrm{~mL}$ of filtrate, $2 \mathrm{~mL}$ of acid ninhydrin, and $2 \mathrm{~mL}$ of glacial acetic acid was taken in a test tube and boiled in water bath at $100{ }^{\circ} \mathrm{C}$ for $30 \mathrm{~min}$. The reaction was terminated on ice, and the reaction mixture was then extracted with $4 \mathrm{~mL}$ of toluene. The solution was vortex mixed and $3 \mathrm{~mL}$ of the upper toluene extract was centrifuged at $4000 \mathrm{~g}$ for $5 \mathrm{~min}$. The absorbance was read at $520 \mathrm{~nm}$. Protein content was assayed using the coomassie brilliant blue G-250 (CBB-G) method as described by Aminian et al. (2013) and the absorbance was read at $595 \mathrm{~nm}$. The soluble sugar contents of the rice leaves were estimated by the method of Karim et al. (2012) with minor modifications. Leaves $(0.2 \mathrm{~g})$ were ground with liquid nitrogen to a fine powder and then added $15 \mathrm{~mL}$ of distilled water to heat at $100{ }^{\circ} \mathrm{C}$ for $20 \mathrm{~min}$. After cooling, $0.1 \mathrm{~mL}$ of filtrate and $5 \mathrm{~mL}$ of enthrone sulfuric acid solution were mixed and then heated at $100{ }^{\circ} \mathrm{C}$ for $10 \mathrm{~min}$ and the absorbance was recorded at $620 \mathrm{~nm}$.

\section{Experimental design and data analysis}

Treatments were arranged according to completely randomized design (CRD) with three replications. The data were analyzed by an analysis of variance (ANOVA) technique with statistical software Statistix 8.0 (Analytical, Tallahassee, Florida, USA) while the differences among means were separated by least significant difference (LSD) test at the 5\% significance level. The Sigma Plot 12.5 (Systat Software Inc., San Jose, CA, USA) was used to make the figures.

\section{Results}

\section{Germination and seedling establishment}

The highest germination rate and the percentage of seedling establishment were observed in SSBM treatment for both cultivars (Fig. 1). DSBM and SSBM significantly increased germination rate for Xiangyaxiangzhan by $9.69 \%$ and $10.53 \%$, respectively, and for Wufengyou 615 by $3.66 \%$ and $3.85 \%$, respectively. However, WSBM treatment obviously reduced germination rate by $4.40 \%$ and $3.77 \%$ for Xiangyaxiangzhan and Wufengyou 615, respectively (Fig. 1 A, B). Seedling establishment was substantially increased in SSBM by $23.66 \%$ and $13.52 \%$ for Xiangyaxiangzhan and Wufengyou615, respectively. For Xiangyaxiangzhan, DSBM treatment significantly increased seedling establishment percentage but WSBM treatment show opposite trend. For Wufengyou 615, DSBM and WSBM did not affect the seedling establishment percentage significantly (Fig. $1 C, D)$.

\section{Morphological growth}

Different seedling establishment methods substantially affected morphological characters of both rice cultivars. For Xiangyaxiangzhan, seedling length, length of first leaf sheet, length of first and second leaf as well as dry biomass were recorded maximum in SSBM and the values were 0.40, 22.01, 66.81, 27.93, 45.37\% and 14.49, $13.65,77.37,28.41,26.00 \%$, and 5.64, 0.72, 65.96, 19.77, 12.39\%, higher than TWSM at 1015 and 20 DAS, respectively (Tables 1 and 2). 
Table 1. The seedling length and shoot dry weight of rice seedlings in response to different seedling raising methods

\begin{tabular}{c|c|c|c|c|c|c|c}
\hline \multirow{2}{*}{ Cultivar } & \multirow{2}{*}{ Treatment } & \multicolumn{3}{|c|}{ Seedling length (cm) } & \multicolumn{3}{c}{ Shoot dry weight (mg) } \\
\cline { 3 - 8 } & & 10 DAS & 15 DAS & 20 DAS & 10 DAS & 15 DAS & 20 DAS \\
\hline \multirow{4}{*}{ Xiangyaxiangzhan } & TWSM & $17.37 \mathrm{a}$ & $19.67 \mathrm{ab}$ & $21.82 \mathrm{a}$ & $10.80 \mathrm{~b}$ & $15.00 \mathrm{~b}$ & $23.40 \mathrm{bc}$ \\
& DSBM & $16.52 \mathrm{a}$ & $19.76 \mathrm{ab}$ & $22.67 \mathrm{a}$ & $11.90 \mathrm{~b}$ & $21.00 \mathrm{a}$ & $21.80 \mathrm{c}$ \\
& WSBM & $17.39 \mathrm{a}$ & $18.03 \mathrm{~b}$ & $19.36 \mathrm{~b}$ & $10.90 \mathrm{~b}$ & $13.40 \mathrm{~b}$ & $25.20 \mathrm{ab}$ \\
& SSBM & $17.44 \mathrm{a}$ & $22.52 \mathrm{a}$ & $23.05 \mathrm{a}$ & $15.70 \mathrm{a}$ & $18.90 \mathrm{a}$ & $26.30 \mathrm{a}$ \\
\hline \multirow{5}{*}{ Wufengyou 615 } & TWSM & $23.23 \mathrm{a}$ & $24.07 \mathrm{a}$ & $29.42 \mathrm{a}$ & $22.00 \mathrm{a}$ & $26.90 \mathrm{a}$ & $47.30 \mathrm{a}$ \\
& DSBM & $18.96 \mathrm{~b}$ & $19.99 \mathrm{~b}$ & $23.30 \mathrm{c}$ & $13.70 \mathrm{~b}$ & $18.00 \mathrm{~b}$ & $33.10 \mathrm{~b}$ \\
& WSBM & $18.58 \mathrm{~b}$ & $19.94 \mathrm{~b}$ & $22.70 \mathrm{c}$ & $12.40 \mathrm{~b}$ & $17.00 \mathrm{~b}$ & $32.10 \mathrm{~b}$ \\
& SSBM & $19.06 \mathrm{~b}$ & $23.24 \mathrm{a}$ & $25.03 \mathrm{~b}$ & $20.00 \mathrm{a}$ & $27.00 \mathrm{a}$ & $47.40 \mathrm{a}$ \\
\hline
\end{tabular}

Different lowercase letters followed by the mean of different treatments in the same column within one variety indicate significant difference at $\mathrm{P}<0.05$ level. TWSM: traditional seedling-raising method, DSBM: dry seedbed nursery raising method, WSBM: wet seedbed raising method, and SSBM: substrate seedbed nursery raising method

Table 2. Effects of different seedling raising methods on leaf and leaf sheath length

\begin{tabular}{|c|c|c|c|c|c|c|c|c|c|c|}
\hline \multirow{2}{*}{ Cultivar } & \multirow{2}{*}{ Treatment } & \multicolumn{3}{|c|}{ First leaf sheath length $(\mathrm{cm})$} & \multicolumn{3}{|c|}{ First leaf length $(\mathrm{cm})$} & \multicolumn{3}{|c|}{ Second leaf length $(\mathrm{cm})$} \\
\hline & & 10 DAS & 15 DAS & 20 DAS & 10 DAS & 15 DAS & 20 DAS & 10 DAS & 15 DAS & 20 DAS \\
\hline \multirow{4}{*}{ Xiangyaxiangzhan } & TWSM & $3.18 \mathrm{~b}$ & $3.59 \mathrm{~b}$ & $4.19 \mathrm{a}$ & $2.35 b$ & $2.43 b$ & $2.82 \mathrm{~b}$ & $9.20 \mathrm{~b}$ & $9.47 \mathrm{c}$ & $10.42 \mathrm{c}$ \\
\hline & DSBM & $3.62 \mathrm{a}$ & $4.08 \mathrm{a}$ & $4.13 \mathrm{a}$ & $3.23 \mathrm{ab}$ & $3.33 \mathrm{ab}$ & $3.68 \mathrm{ab}$ & $9.47 \mathrm{~b}$ & $11.23 \mathrm{ab}$ & $11.64 \mathrm{ab}$ \\
\hline & WSBM & $3.22 \mathrm{~b}$ & $3.36 \mathrm{~b}$ & $3.58 \mathrm{a}$ & $3.06 \mathrm{ab}$ & $3.22 b$ & $3.51 \mathrm{ab}$ & $10.53 \mathrm{ab}$ & $10.53 \mathrm{bc}$ & $11.17 \mathrm{bc}$ \\
\hline & SSBM & $3.88 \mathrm{a}$ & $3.90 \mathrm{ab}$ & $4.16 \mathrm{a}$ & $3.92 \mathrm{a}$ & $4.31 \mathrm{a}$ & $4.68 \mathrm{a}$ & $11.77 \mathrm{a}$ & $12.16 \mathrm{a}$ & $12.48 \mathrm{a}$ \\
\hline \multirow{4}{*}{ Wufengyou 61} & $\mathrm{TW}$ & 3 & 3 & & $2.70 \mathrm{a}$ & $\mathrm{ab}$ & 3.5 & $7.43 b$ & $9.83 \mathrm{ab}$ & $10.28 \mathrm{~b}$ \\
\hline & DSBM & $3.33 \mathrm{ab}$ & $3.72 \mathrm{a}$ & $4.16 \mathrm{ab}$ & $2.66 \mathrm{a}$ & $2.91 \mathrm{ab}$ & $3.40 \mathrm{~b}$ & $9.00 \mathrm{a}$ & $9.18 \mathrm{~b}$ & $10.34 b$ \\
\hline & WSBM & $2.94 \mathrm{~b}$ & $3.34 \mathrm{a}$ & $3.58 \mathrm{~b}$ & $2.31 \mathrm{~b}$ & $2.43 b$ & $2.76 \mathrm{~b}$ & $6.06 \mathrm{c}$ & $9.00 \mathrm{~b}$ & $9.44 \mathrm{c}$ \\
\hline & SSBM & $3.09 \mathrm{ab}$ & $3.66 \mathrm{a}$ & $4.35 \mathrm{a}$ & $2.72 \mathrm{a}$ & $3.01 \mathrm{a}$ & $4.43 \mathrm{a}$ & 8.39ab & $10.81 \mathrm{a}$ & $13.61 \mathrm{a}$ \\
\hline
\end{tabular}

Different lowercase letters follow by the mean of different treatments in the same column within one variety indicate significant difference at $\mathrm{P}<0.05$ level. TWSM: traditional seedling-raising method, DSBM: dry seedbed nursery raising method, WSBM: wet seedbed raising method, and SSBM: substrate seedbed nursery raising method

For Wufengyou 615, seedling length was considerably reduced under all seedling establishment methods at all sampling intervals, compared with TWSM. Moreover, SSBM was found statistically at par $(P>0.05)$ with TWSM and/or higher than other seedling establishment methods regarding length of first leaf sheet (at all sampling intervals), first leave length (at 10 and 15 DAS). The second leaf length were recorded maximum in DSBM at 10 DAS while at 15 and 20 DAS, the second leaf length was highest in SSBM. The dry biomass were also remained maximum in SSBM (higher than other two seedling establishment methods) but statistically similar $(P>0.05)$ with TWSM at 10, 15 and 20 DAS. Overall, the morphological parameters were increased with an increase in seedling age (from 10 to 20 DAS) in both Xiangyaxiangzhan and Wufengyou 615. 


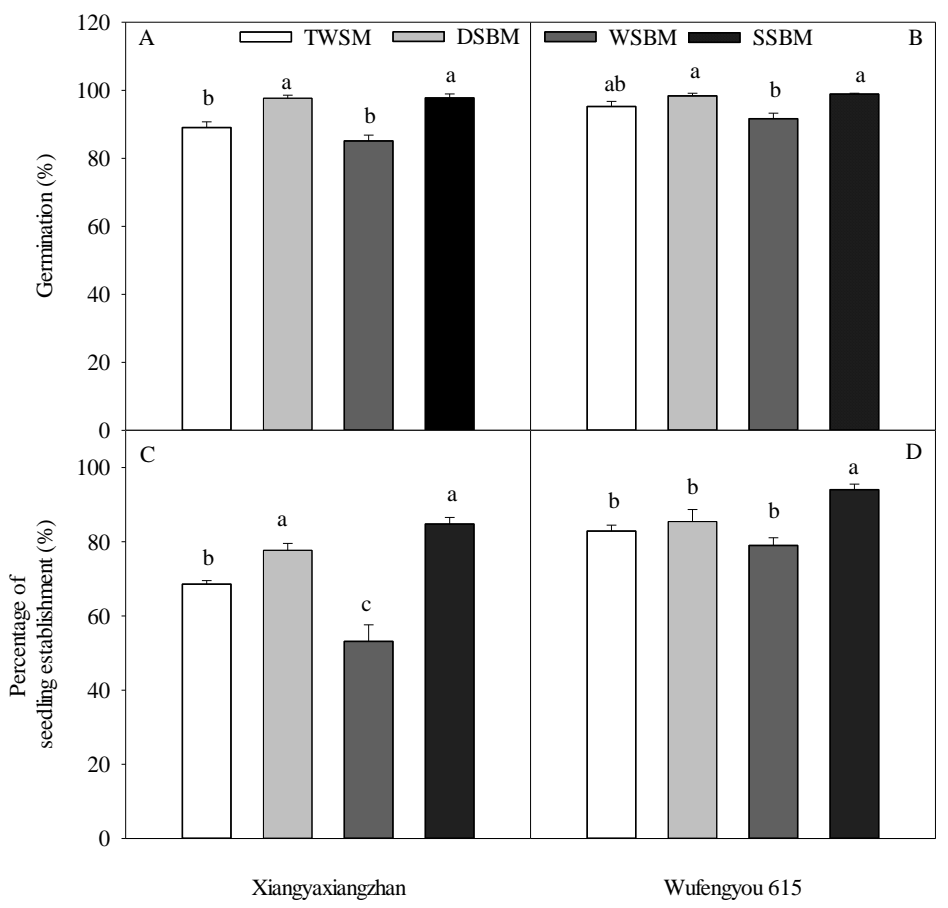

Figure 1. The seed germination rate and percentage of seedling establishment in response to the different seedling raising methods for Xiangyaxiangzhan $(A, C)$ and Wufengyou 615 (B, $D$ ). Different lowercase letters followed by the mean of different treatments within one variety indicate significant difference at $P<0.05$ level. TWSM: traditional seedling-raising method, DSBM: dry seedbed nursery raising method, WSBM: wet seedbed raising method, and SSBM: substrate seedbed nursery raising method

Furthermore, differential responses of both rice cultivars regarding root morphological characters were noted under different seedling establishment methods. For example, root numbers, root length, root surface area and root diameter were higher in modified seedling establishment methods than TWSM whilst SSBM proved better than other methods (Table 3). For Xiangyaxiangzhan 44.41, 36.42, 19.81, 18.75 and $3.37,13.52,19.01,33.33 \%$, and 19.15, 23.24, 13.94, 85.71\% higher root numbers, root length, root surface area and root diameter were recorded in SSBM at 10, 15 and 20 DAS, respectively. Similarly, for Wufengyou 615, 42.51, and 18.63, $19.81 \%$ higher root numbers $31.95,32.26$, and $23.25 \%$ higher root length, 44.33, 45.99 and $40.83 \%$ higher root surface area, 9.68, 112.00 and $65.43 \%$ higher root diameter were recorded at 10, 15 and 20 DAS, respectively.

Table 3. Effects of different seedling raising methods on the morphological indexes of root

\begin{tabular}{|c|c|c|c|c|c|c|c|c|c|c|c|c|c|}
\hline \multirow{2}{*}{ Cultivar } & \multirow{2}{*}{ Treatment } & \multicolumn{3}{|c|}{ Number of root } & \multicolumn{3}{|c|}{ Number of the white root } & \multicolumn{3}{|c|}{ Root length(cm) } & \multicolumn{3}{|c|}{ Diameter (mm) } \\
\hline & & 10 DAS & 15 DAS & 20 DAS & 10 DAS & 15 DAS & 20 DAS & 10 DAS & 15 DAS & 20 DAS & 10 DAS & 15 DAS & 20 DAS \\
\hline \multirow{4}{*}{ 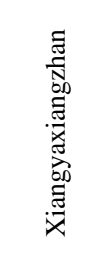 } & TWSM & $9.12 \mathrm{c}$ & $14.83 \mathrm{a}$ & $14.83 \mathrm{~b}$ & $1.86 \mathrm{~b}$ & $2.84 \mathrm{c}$ & $2.77 \mathrm{c}$ & $64.55 b$ & $84.00 \mathrm{~b}$ & $157.21 b$ & $0.32 \mathrm{a}$ & $0.33 \mathrm{a}$ & $0.42 b$ \\
\hline & DSBM & $11.81 \mathrm{ab}$ & $14.19 \mathrm{ab}$ & $14.50 \mathrm{~b}$ & $10.37 \mathrm{a}$ & $11.28 \mathrm{~b}$ & $11.90 \mathrm{~b}$ & $73.79 \mathrm{~b}$ & $93.06 \mathrm{ab}$ & $178.42 \mathrm{ab}$ & $0.32 \mathrm{a}$ & $0.38 \mathrm{a}$ & $0.47 \mathrm{~b}$ \\
\hline & WSBM & $11.07 \mathrm{bc}$ & $12.50 \mathrm{~b}$ & $13.00 \mathrm{~b}$ & $1.93 \mathrm{~b}$ & $2.89 \mathrm{c}$ & $2.45 \mathrm{c}$ & $69.59 \mathrm{~b}$ & $92.13 \mathrm{ab}$ & $178.8 \mathrm{ab}$ & $0.31 \mathrm{a}$ & $0.35 a$ & $0.62 \mathrm{ab}$ \\
\hline & SSBM & $13.17 \mathrm{a}$ & $15.33 \mathrm{a}$ & $17.67 \mathrm{a}$ & $11.89 \mathrm{a}$ & $13.73 \mathrm{a}$ & $15.38 \mathrm{a}$ & $88.06 \mathrm{a}$ & $95.36 \mathrm{a}$ & $193.75 \mathrm{a}$ & $0.38 \mathrm{a}$ & $0.44 \mathrm{a}$ & $0.78 \mathrm{a}$ \\
\hline
\end{tabular}




\begin{tabular}{|c|c|c|c|c|c|c|c|c|c|c|c|c|c|}
\hline \multirow{4}{*}{ 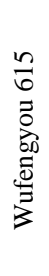 } & TWSM & $12.28 \mathrm{~b}$ & $15.67 \mathrm{bc}$ & $16.00 \mathrm{bc}$ & $2.67 \mathrm{c}$ & $3.31 \mathrm{c}$ & $3.82 \mathrm{~b}$ & $61.29 \mathrm{~b}$ & $74.05 \mathrm{c}$ & $184.53 \mathrm{c}$ & $0.31 \mathrm{a}$ & $0.25 b$ & $0.81 \mathrm{c}$ \\
\hline & DSBM & $13.06 \mathrm{~b}$ & $16.33 \mathrm{~b}$ & $17.00 \mathrm{~b}$ & $11.84 \mathrm{~b}$ & $12.44 \mathrm{~b}$ & $15.25 \mathrm{a}$ & $82.45 \mathrm{a}$ & $83.95 b$ & $207.48 \mathrm{ab}$ & $0.33 a$ & $0.46 \mathrm{a}$ & $1.16 \mathrm{~b}$ \\
\hline & WSBM & $13.33 b$ & $13.77 \mathrm{c}$ & $15.00 \mathrm{c}$ & $2.84 \mathrm{c}$ & $3.29 \mathrm{c}$ & $4.33 b$ & $71.05 \mathrm{ab}$ & $91.14 \mathrm{ab}$ & $203.09 \mathrm{bc}$ & $0.30 \mathrm{a}$ & $0.51 \mathrm{a}$ & $1.16 \mathrm{~b}$ \\
\hline & SSBM & $17.50 \mathrm{a}$ & $18.59 \mathrm{a}$ & $19.17 \mathrm{a}$ & $13.48 \mathrm{a}$ & $16.23 \mathrm{a}$ & $16.27 \mathrm{a}$ & $80.87 a$ & $97.94 \mathrm{a}$ & $227.43 \mathrm{a}$ & $0.34 \mathrm{a}$ & $0.53 \mathrm{a}$ & $1.34 \mathrm{a}$ \\
\hline
\end{tabular}

Different lowercase letters follow by the mean of different treatments in the same column within one variety indicate significant difference at $\mathrm{P}<0.05$ level. TWSM: traditional seedling-raising method, DSBM: dry seedbed nursery raising method, WSBM: wet seedbed raising method, and SSBM: substrate seedbed nursery raising method

\section{Physiological characters and SPAD values}

Seedling raising methods variably affected physiological characters i.e., leaf proline, protein and soluble sugar contents as well as leaf chlorophyll contents (in terms of SPAD) values of both rice cultivars. Leaf proline contents were improved significantly $(P<0.05)$ in rice seedlings raised by SSBM method (except at 15 DAS in Xiangyaxiangzhan) than other raising method including TWSM at all sampling stages in both rice cultivars (Fig. 2).

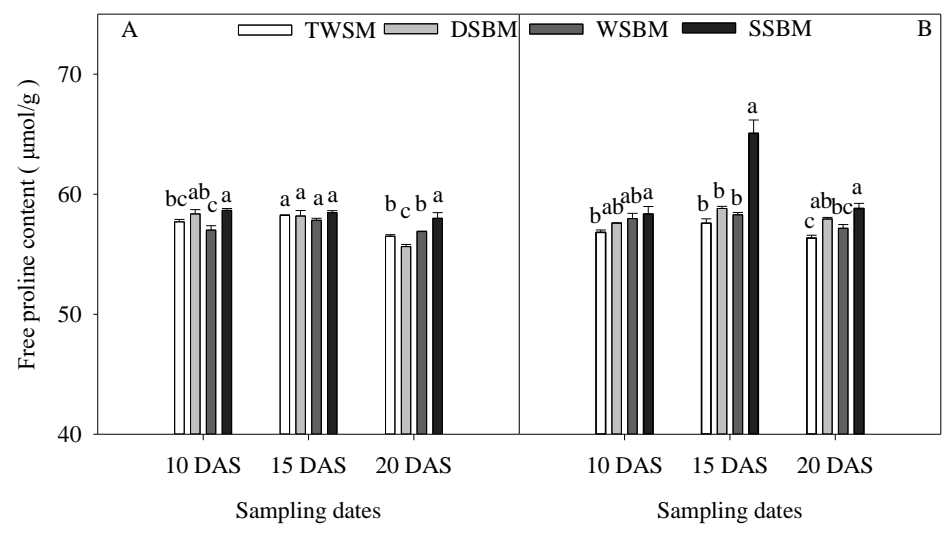

Figure 2. Effects of different seedling raising methods on proline content in leaves of seedlings for two cultivars (A: Xiangyaxiangzhan; B: Wufengyou 615). Different lowercase letters followed by the mean of different treatments within one variety indicate significant difference at $P<0.05$ level. TWSM: traditional seedling-raising method, DSBM: dry seedbed nursery raising method, WSBM: wet seedbed raising method, and SSBM: substrate seedbed nursery raising method

The leaf protein contents were remained highest in the seedlings raised by SSBM method which was remained statistically similar $(P>0.05)$ with WSBM and TWSM and minimum were recorded in DSBM at 10 DAS. At 15 DAS, maximum protein contents were recorded in the leaves of Wufengyou 615 established by DSBM followed by TWSM, SSBM while minimum in WSBM (Fig. 3). Further, at 20 DAS, the leaf proline contents were remained statistically similar $(P>0.05)$ for all seedling establishment methods. The SSBM resulted in higher soluble sugar contents for both rice cultivars at 10 and 15 DAS, however, at 20 DAS; the maximum soluble sugars were recorded in TWSM whilst minimum in WSBM and DSBM in Xiangyaxiangzhan 
and Wufengyou 615, respectively (Fig. 4). Overall, the soluble sugar contents were increased with increase in seedling age from 10 to 20 DAS for Xiangyaxiangzhan, and increased from 10 to 15 DAS and then reduced to 20 DAS in Wufengyou 615. Furthermore, all seedling raising methods remained statistically similar $(P>0.05)$ for leaf protein contents for Xiangyaxiangzhan at all sampling stages, while affected differently at 10 and 15 DAS for Wufengyou 615 (Fig. 3). Regarding SPAD values, maximum values were recorded at SSBM at all sampling stages and the values of percentage increase were 15.21, 17.56, and 24.12\% in Xiangyaxiangzhan at 10, 15 and 20 DAS (Fig. 5). For Wufengyou 615, highest SPAD values were recorded in the seedlings raised by SSBM method at all sampling stages and the values were significantly higher than other seedling raising methods and TWSM.

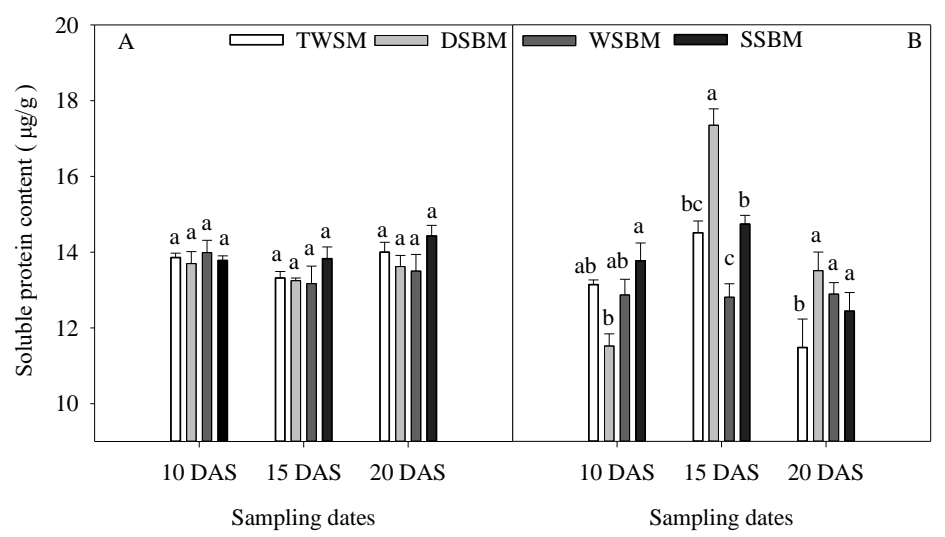

Figure 3. Effects of different seedling raising methods on soluble protein content in leaves of seedlings for two cultivars (A: Xiangyaxiangzhan; B: Wufengyou 615). Different lowercase letters followed by the mean of different treatments in the same column within one variety indicate significant difference at $P<0.05$ level. TWSM: traditional seedling-raising method, DSBM: dry seedbed nursery raising method, WSBM: wet seedbed raising method, and SSBM: substrate seedbed nursery raising method

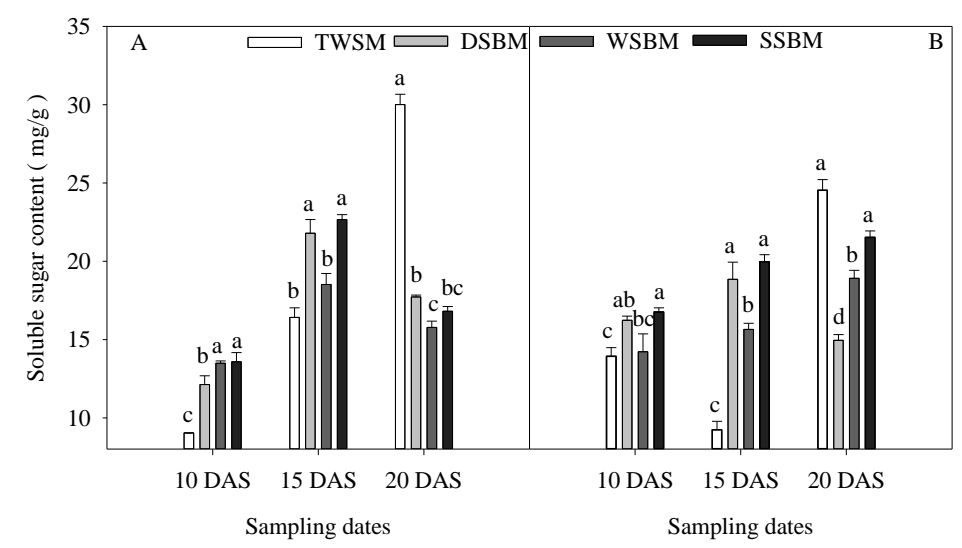

Figure 4. Effects of different seedling raising methods on soluble sugar content of seeding for two cultivars (A: Xiangyaxiangzhan; B: Wufengyou 615). Different lowercase letters followed by the mean of different treatments within one variety indicate significant difference at $P<0.05$ level. TWSM: traditional seedling-raising method, DSBM: dry seedbed nursery raising method, WSBM: wet seedbed raising method, and SSBM: substrate seedbed nursery raising method 


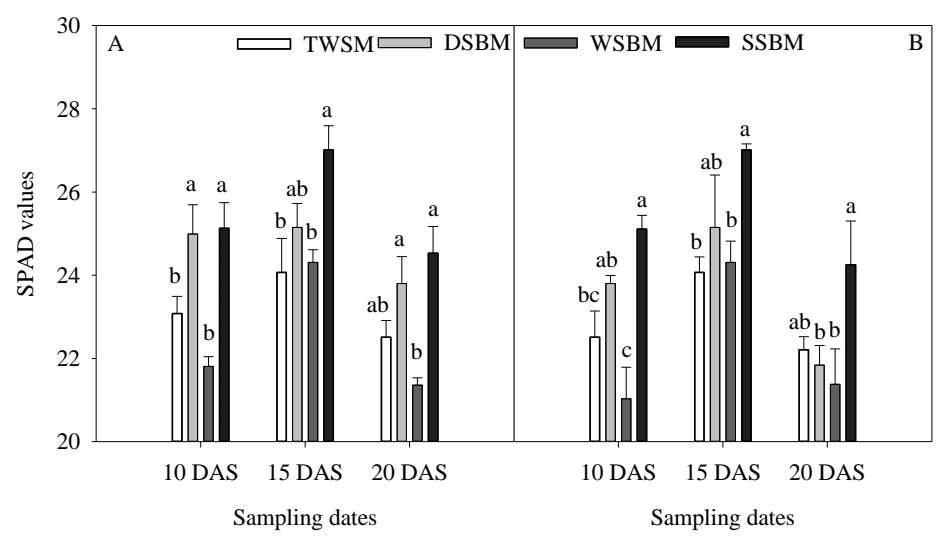

Figure 5. Effects of different seedling raising methods on SPAD values of seeding for two cultivars (A: Xiangyaxiangzhan; B: Wufengyou 615). Different lowercase letters followed by the mean of different treatments within one variety indicate significant difference at $P$

$<0.05$ level. TWSM: traditional seedling-raising method, DSBM: dry seedbed nursery raising method, WSBM: wet seedbed raising method, and SSBM: substrate seedbed nursery raising method

\section{Correlation analysis}

There was no significant correlation between shoot dry weight at 10 DAS and seedling establishment for Wufengyou 615 (Fig. 6 A). Only Xiangyaxianzhan presented a high positive correlation between shoot dry weight at 10 DAS and seedling establishment $(\mathrm{r}=0.6686, P<0.05)$, indicating same effects of different seedling raising methods on the shoot dry weight and seedling establishment for this variety. There was however a high $(P<0.05)$ positive correlation between shoot dry weight at 15 DAS and seedling establishment for both cultivars (Fig. 6 $B)$ where the correlation coefficients $(r)$ are $0.5792(P<0.05)$ for Wufengyou 615 and $0.7849(P<0.01)$ for Xiangyaxiangzhan. This result suggests that the increased percentage of seedling establishment is closely linked to shoot dry weight. Further, shoot dry weight at 15 DAS was positively associated with leaf sheath length at all sampling dates, but the significance was only recorded for Wufengyou 615 and 20 DAS in Xiangyaxiangzhan (Fig. 6 C, D, E). In addition, the positive associations were also recorded for the percentage of seedling establishment with germination rate, SPAD values at 15 DAS, number of roots and white roots at all dates for the two cultivars (Fig. 7).

\section{Discussion}

Rice seed germination and seedling growth is affected by the seed viability and vigour, nature of the growing medium, water application and the various other external factors. These external factors might be promoting or inhibitory and the effects of these factors on the rice nursery and/or seedling growth vary overtime. In this study, highest germination rate and seedling establishment in SSBM may possibly due to fertile growing medium of amorphous nature (non-compacted) with significant amount of organic matter. Our results are in concomitant with the findings of Mishra and Salokhe (2008), who found in reduced soil environments (under aerobic conditions), the coleoptile of the rice seeds were poorly developed 
than flooded soil. Further, type of growing media and growing environments determine the quality of the seedlings growing in it for nursery raising (Wilson, 2001; Agbo and Omaliko, 2006), which have significant impacts on its later growth and performance in the field after transplanting (Baiyeri, 2006). Hence, higher seed germination and seedling establishment in SSBM indicates their relations with the type of growing medium.
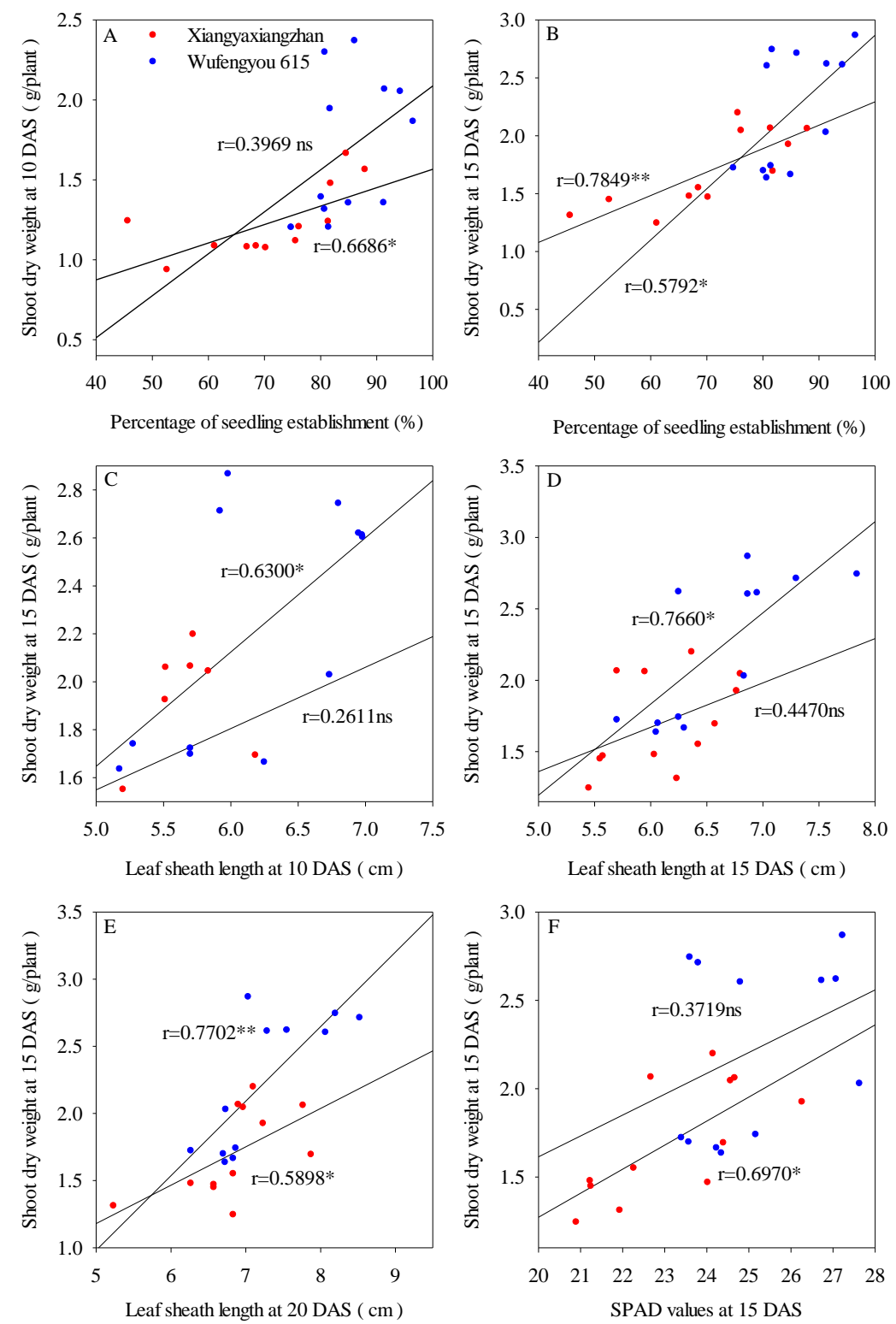

Figure 6. Correlation analyses between (A) shoot dry weight at 10 DAS and percentage of seedling establishment, $(B)$ percentage of seedling establishment and shoot dry weight at 15 $D A S,(C)$ shoot dry weight at 15 DAS and leaf sheath at 10 DAS, (D) shoot dry weight at 15 $D A S$ and leaf sheath length at 15 DAS, (E) shoot dry weight at 15 DAS and leaf sheath length at 20 DAS, $(F)$ shoot dry weight at 15 DAS and SPAD values at 15 DAS for Xiangyaxiangzhan and Wufengyou 615, respectively. ns: non-significant at $P<0.05$ level; *: significant at $P<0.05$ levels; **: significant at $P<0.01$ levels 


$$
-1409 \text { - }
$$
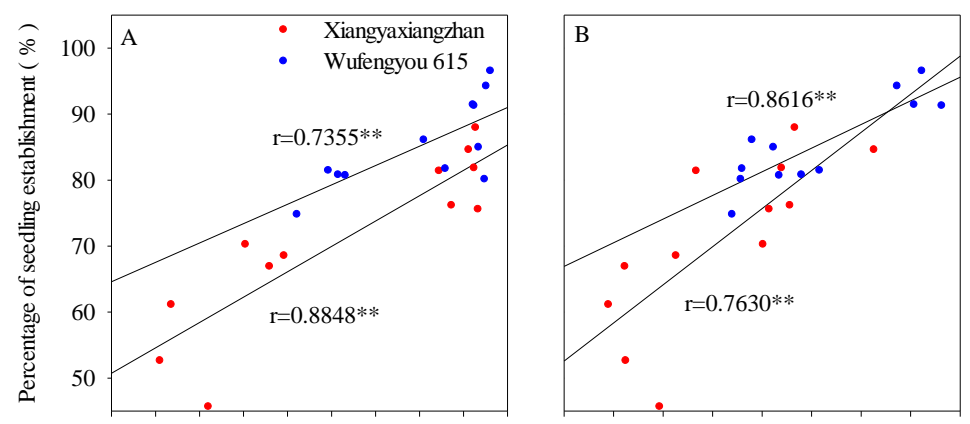

$\begin{array}{llllllllll}82 & 84 & 86 & 88 & 90 & 92 & 94 & 96 & 98 & 100\end{array}$
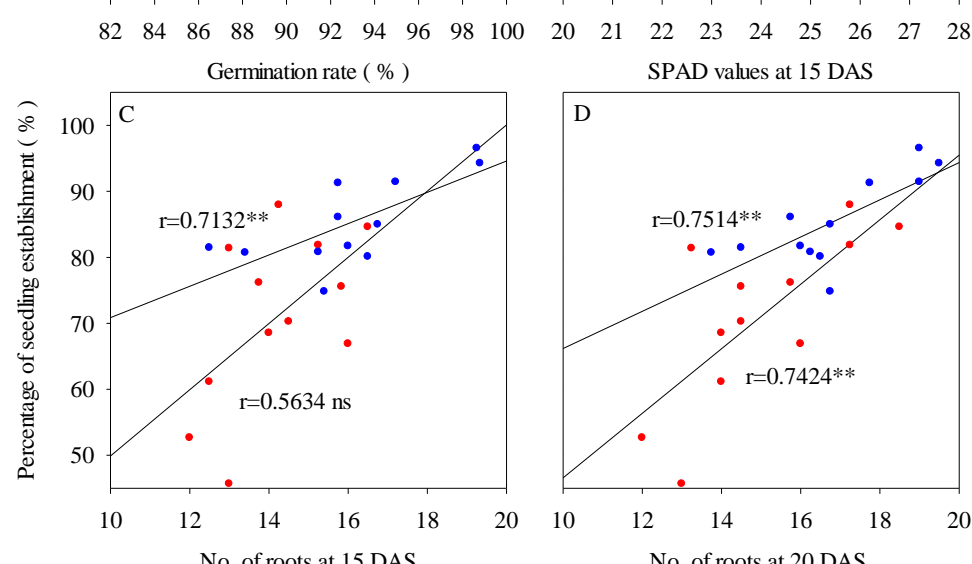

SPAD values at 15 DAS
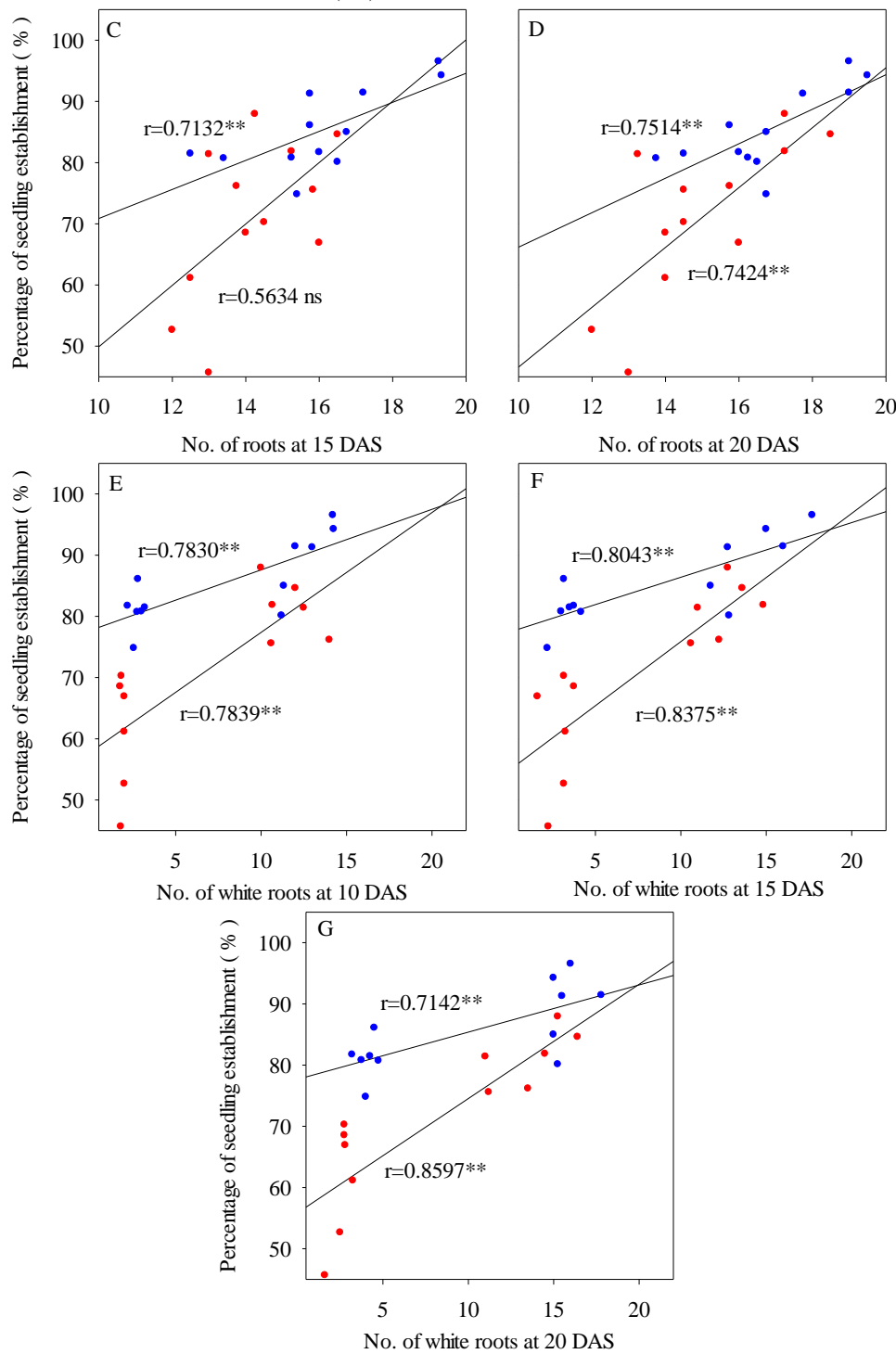

Figure 7. Correlation analyses between (A) percentage of seedling establishment and germination rate, $(B)$ percentage of seedling establishment and SPAD values at 15 DAS, $(C)$ percentage of seedling establishment and the No. of roots at 15 DAS, $(D)$ percentage of seedling establishment and No. of roots at 20 DAS, (E) percentage of seedling establishment and the No. of white roots at $10 \mathrm{DAS},(F)$ percentage of seedling establishment and the No. of white roots at $15 \mathrm{DAS}$, and $(G)$ percentage of seedling establishment and the No. of white roots at 20 DAS for Xiangyaxiangzhan and Wufengyou 615, respectively. ns: non-significant at $P<0.05$ level; **: significant at $P<0.01$ levels 
Different seedling establishment methods substantially affected morphological characters of both rice cultivars. Development of shoot and leaves along with the growth of roots is prerequisite or transitory phase for rice seeds from heterotrophic to autotrophic level (Sasaki, 2004). Our results revealed that nursery management practices and type of nursery growing medium influenced growth and development of rice seedlings. Better root growth with higher root surface area in SSBM mimics in shoot growth with seedling length, leaf length and dry biomass. Ros et al. (2003) argued that rice seedlings establishment and their consequent growth not only related to above-ground morphological characters but also on the root growth and development. Raising healthy and well-established seedlings with well-flourished and healthy root system or simply, the morphogenesis of rice seedlings might have strong associations with nature and type of seedbed and/or growing media, number of seeds per area and soil conditions (Yamauchi and Biswas, 1997). Hence, root elongation under modified nursery raising methods, especially SSBM, showed that use of substrate (organic in nature) of rice seedlings favors root formation and seedling development. Furthermore, Subedi et al. (2013) also stated that nursery management practices considerably influence seedling characteristics of low land rice, whereas Panda et al. (1991) reported that seedlings raised in nutritious seed-bed would result in healthy and vigorous seedlings and performs better in the field conditions.

Moreover, seedling raising methods variably affected physiological characters i.e., leaf proline, protein and soluble sugar contents and leaf chlorophyll contents (in terms of SPAD) values of both rice cultivars. Overall, seedlings grown by substrate method also performed physiologically better than other nursery establishment methods, while all other modified seedling raising methods also proved better than TWSM (normally practiced by the farmers). Previously, Thakur et al. (2010) also reported rice establishment method induced regulations in physiological characters of rice seedlings. Higher chlorophyll contents in the leaves would lead to increased photosynthesis, hence improved seedling growth. Dark green leaves with higher SPAD values were observed in modified seedling establishment methods than TWSM. These findings are in accordance with Harper et al. (2004) and Thakur et al. (2010). Overall, the results of this study depicted that improved seedling establishment methods with better growing medium may induce multiple, positive and significant changes in morphogenesis, phenotype and growth of rice seedlings, however, evoking these changes and responses of rice nursery to the specific seed establishment methods yet need to be studied and their performance in the field conditions as well. Hence, keeping in view this point, field based evaluation of rice nursery managed by different rice nursery establishment methods would thus be focused in our subsequent experiments to draw a most comprehensive inference.

\section{Conclusion}

In sum, different seedling raising methods significantly affect rice seedling growth and seedling establishment. Among modified rice seedling raising methods, SSBM proved better for both Xiangyaxiangzhan and Wufengyou 615 rice cultivars. Along with morphological growth, significant improvements were also observed in physiological characteristics of the seedlings of both rice cultivars. Hence, addition of organic manure contained material in the growing media of rice nursery may improve morphphysiological features of rice seedlings for the purpose of better stand establishment in the paddy fields. 
Acknowledgements. Founding provides by Agricultural research project of Guangdong Province (2011AO20202001), and Agricultural standardization project in Guangdong Province (4100F10003) is highly acknowledged.

\section{REFERENCES}

[1] Abid, M., Khan, I., Mahmood, F., Aahraf, U., Imranm, M., Anjum, S. A. (2015): Response of hybrid rice to various transplanting dates and nitrogen application rates. Philippine Agric Scientist 98(1): 98-104.

[2] Agbo, C. U., Omaliko, C. M. (2006): Initiation and growth of shoots of Gongronema latifolia benth. Stem cuttings in different rooting media. - African J Biotechnol 5(5): 425428.

[3] Aminian, M., Nabatchian, F., Vaisi-raygan, A., Torabi, M. (2013): Mechanism of Coomassie Brilliant Blue G-250 binding to cetyltrimethylammonium bromide: an interference with the Bradford assay. - Anal Biochem 434(2): 287-291.

[4] Asai, H., Samson, B. K., Stephan, H. M., Songyikhangsuthor, K., Homma, K., Kiyono, Y., Inoue, Y., Shairaiwa, T., Horie, T. (2009): Biochar amendment techniques for upland rice production in Northern Laos: 1. Soil physical properties, leaf SPAD and grain yield. - Field Crops Research 111(1): 81-84.

[5] Ashraf, U., Kanu, A. S., Mo, Z. W., Hussain, S., Anjum, S. A., Khan, I., Abbas, R. N., Tang, X. R. (2015): Lead toxicity in rice: effects, mechanisms, and mitigation strategies - a mini review. - Environ Sci Pollut Res 22(23): 18318-18332.

[6] Baiyeri, K. P. (2006): Seedling emergence and growth of pawpaw (Carica papaya) grown under different coloured shade polyethylene. - International Agrophysics 20(2): 77-84.

[7] Biswas, J. C., Ladha, J. K., Dazzo, F. B., Yanni, Y. G., Rolfe, B. G. (2000): Rhizobial inoculation influences seedling vigor and yield of rice. - Agronomy Journal 92(5): 880886.

[8] Celik, O., Atak, C. (2012): The effect of salt stress on antioxidative enzymes and proline content of two Turkish tobacco varieties. - Turkish Journal of Biology 36: 339-356.

[9] Ehsanullah, Anjum, S. A., Ashraf, U., Rafig, H., Tanveer, M., Khan, I. (2014): Effect of sowing dates and weed control methods on weed infestation, growth and yield of directseeded rice. - Philippine Agric Scientist 97(3): 307-312.

[10] Harper, A. L., Von Gesjen, S. E., Linford, A. S., Peterson, M. P., Faircloth, R. S., Thissen, M. M., Brusslan, J. A. (2004): Chlorophyllide a oxygenase mRNA and protein levels correlate with the chlorophyll $\mathrm{a} / \mathrm{b}$ ratio in Arabidopsis thaliana. - Photosynthesis Research 79(2): 149-159.

[11] Ivanic, M., Martin, W. (2008): Implications of higher global food prices for poverty in low-income countries. - Agricultural economics 39: 405-416.

[12] Kargbo, M. B., Pan, S. G., Mo, Z. W., Wang, Z. M., Luo, X. W., Tian, H., Hossain, M. F., Ashraf, U., Tang, X. R. (2016): Physiological basis of improved performance of super rice (Oryza sativa) to deep placed fertilizer with precision hill-drilling machine. - Int $\mathbf{J}$ Agric Biol 18: 797-804.

[13] Karim, M. A., Komdo, T., Ueda, K., Higuchi, H., Nawata, E. (2012): Effect of NaCl treatment on growth and some physiological characteristics of a salt-tolerant soybean genotype AGS 313 bred in Bangladesh. - Tropical Agri Develop 56(4): 139-142.

[14] Li, M. J., Aahraf, U., Tian, H., Mo, Z. W., Pan, S. G., Anjum, S. A., Tang, X. R. (2016): Manganese-induced regulations in growth, yield formation, quality characters, rice aroma and enzyme involved in 2-acetyl-1-pyrroline biosynthesis in fragrant rice. - Plant Physiol Biochem 103: 167-175.

[15] Li, Q. D. (2015): Level of rice planting mechanization over 38\%. - Agriculture Machinery Technology Extension 1: 12 (in Chinese). 
[16] Li, Y. X., Xing, X. M., Li, G. H. (2014): Study of the Quality and Growth Characteristics in Field About water Volume of Machine Transplanting Seedling. - 2014 National Youth Symposium on the Cultivation and Physiology of Crops: Yangzhou, Jiangsu, China (in Chinese).

[17] Mishra, A., Salokhe, V. M. (2008): Seedling characteristics and the early growth of transplanted rice under different water regimes. - Exp Agri 44(03): 365-383.

[18] Mo, Z. W., Li, W., Pan, S. G., Fitzgerald, T. L., Xiao, F., Tang, Y. J., Tang, X. R. (2015): Shading during the grain filling period increases 2-acetyl-1-pyrroline content in fragrant rice. - Rice 8(9): 1-10.

[19] Oršanić, M., Drvodelić, D., Ugarković, D. (2011): Ecological and Biological Properties of Holm Oak (Quercus ilex L.) on the Island of Rab. - Croatian J Forest Eng 32(1): 4142.

[20] Panda, M. M., Reddy, M. D., Sharma, As. R. (1991): Yield performance of rainfed lowland rice as affected by nursery fertilization under conditions of intermediate deep water $(15-50 \mathrm{~cm})$ and flash floods. - Plant and Soil 132(1): 65-71.

[21] Ros, C., Bell, R. W, White, P. F. (2003): Seedling vigour and the early growth of transplanted rice (Oryza sativa). - Plant and Soil 252(2): 325-337.

[22] Ruiz-Sánchez, M., Aroca, R., Muñoz, Y., Polon, R., Ruiz-lozano, J. M. (2010): The arbuscular mycorrhizal symbiosis enhances the photosynthetic efficiency and the ant oxidative response of rice plants subjected to drought stress. - Journal of Plant Physiology 167(11): 862-869.

[23] Sasaki, R. (2004): Characteristics and seedling establishment of rice nursling seedlings. Japan Agricultural Research Quarterly 38(1): 7-13.

[24] Subedi, R. (2013): Nursery management influences yield and yield attributes of rainfed lowland rice. - Journal of Sustainable Society 2(4): 86-91.

[25] Thakur, A. K, Uphoff, N., Antony, E. (2010): An assessment of physiological effects of system of rice intensification (SRI) practices compared with recommended rice cultivation practices in India. - Experimental Agriculture 46(01): 77-98.

[26] Wilson, S. B, Stoffella, P. J, Graetz, D. A. (2001): Use of compost as a media amendment for containerized production of two subtropical perennials. - Journal of Environmental Horticulture 19(1): 37-42.

[27] Yamauchi, M., Biswas, J. K. (1997): Rice cultivar difference in seedling establishment in flooded soil. - Plant and Soil 189(1): 145-153.

[28] Yang, M. J., Yang, L., Li, Q. D. (2003): Agricultural mechanization system of rice production of Japan and proposal for China. - Transactions of the CSAE 19(5): 77-82.

[29] Yao, F., Xu, Y., Lin, E., Yokozawa, M., Zhang, J. (2007): Assessing the impacts of climate change on rice yields in the main rice areas of China. - Climatic Change 80(3-4): 395-409.

[30] Zhang, H. C, Gong, J. L. (2014): Research status and development discussion on highyielding agronomy of mechanized planting rice in China. - Scientia Agricultura Sinica 47(7): 1273-1289 (in Chinese).

[31] Zhu, D. F, Chen, H. Z, Xu, Y. C. (2007): Countermeasure and perspective of mechanization of rice planting in China. - Northern Rice 05: 13-18 (in Chinese). 